\title{
PRACTICAL OPTIMIZATION OF STEEL HIGHWAY BRIDGE BEAMS
}

\section{DECEMBER 1971 - NUMBER 23}

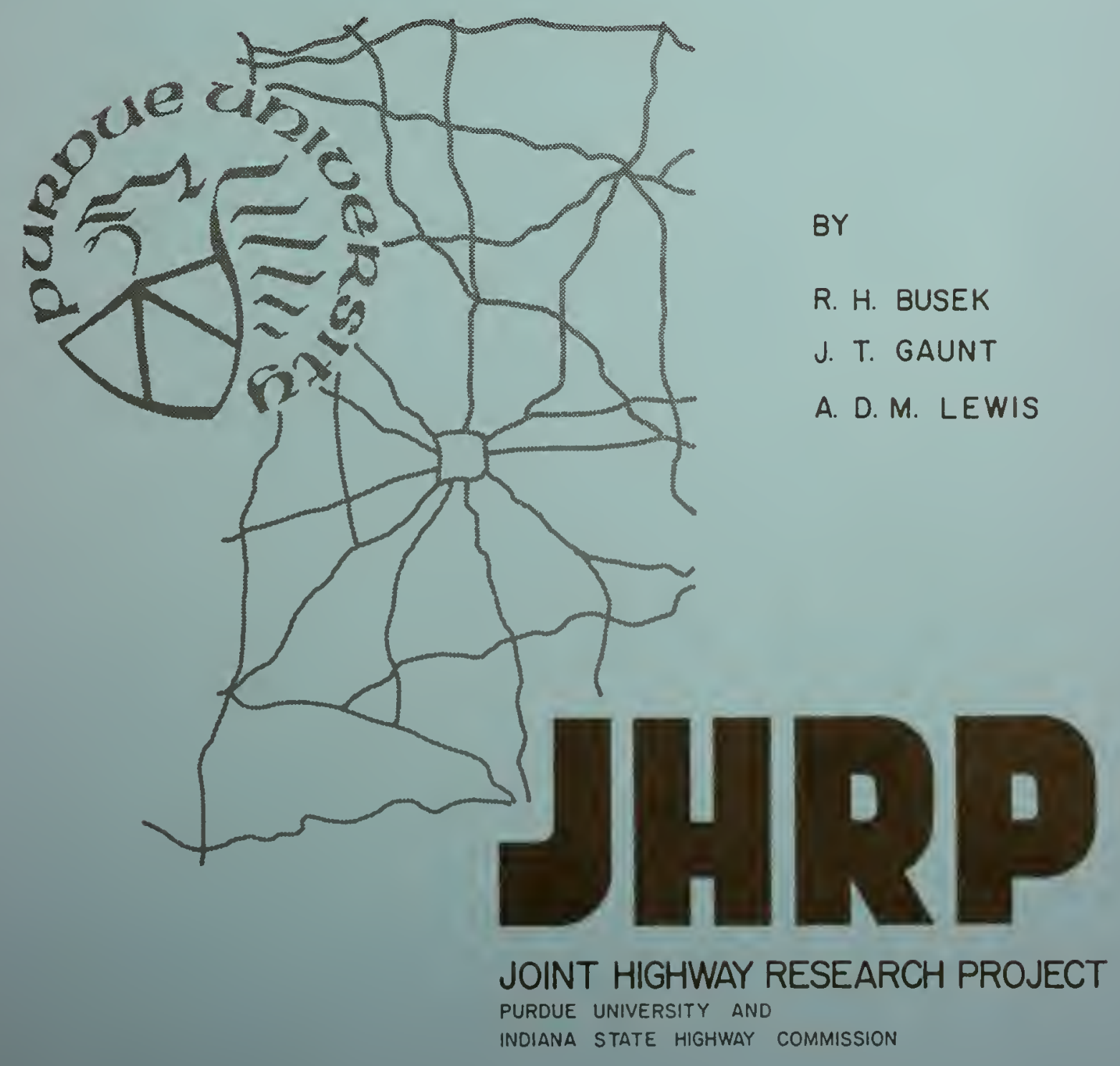



PRACTICAL OPTIMIZATION OF STEEL HIGHWAY BRIDGE BEAMS

T0: J. F. Mclaughlin, Director Joint Highway Research Project

FROM: H. L. Michael, Associate Director Joint Highway Research Project
December 28,1971

Project: C $-36-56 Q$

File: $\quad 7-4-17$

The attached Technical Paper "Practical Optimization of Steel Highway Bridge Beams" has been authored by Messrs. R. H. Busek, J. T. Gaunt, and A. D. M. Lewis, members of the staff of the School of Civil Engineering. Mr. Busek performed the research resulting in this paper as a Graduate Assistant in Research on our staff.

The material in the paper is a summary of a research report presented to the Board at an earlier date. The paper is scheduled for presentation at the 1972 Annual Meeting of the Highway Research Board in Washington, D. C. in January. It is also planned for publication by that organization.

The paper is presented to the Board for approval of presentation and publication as noted.

Respectfully submitted,

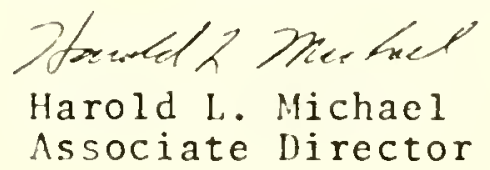

HLM:ms
cc: W. L. Dolch
W. H. Goetz
W. L. Grecco
M. J. Gutzwiller
G. K. Hallock
M. E. Harr

R. H. Harrell
M. L. Hayes
R. D. Miles
J. W. Miller
C. F. Scholer
M. B. Scott

W. T. Spencer

J. A. Spooner

N. W. Steinkamp

H. R. J. Walsh

K. B. Woods

E. J. Yoder 
Technical Paper

PRACTICAL OPTIMIZATION OF STEEL HIGHWAY BRIDGE BEAMS

by

R. H. Busek

J. T. Gaunt

A. D. M. Lewis

Joint Highway Research Project

Project No.: C-36-56Q

File No.: 7-4-17

Purdue University

tafayette, Indiana

December 28,1971 
PRACTICAL OPTIMIZATION OF STEEL HIGHWAY BRIDGE BEAMS

by

R. H. Busek, Structural Engineer

N. H. Bettigole Conpany

New York, New York

(Formerly Research Assistant,

Purdue University)

J. T. Gaunt, Assistant Professor of Clvil Engineering

Purdue University, Lafayette, Indiana

A. D. M. Lewis, Associate Professor of Civil Engineering

Purdue University, Lafayette, Indiana

\section{ABSTRACT}

The cost optimization of a highway bridge girder, composed of a rolled section acting compositely with the bridge deck, is formulated and programmed. An objective function, based on the material and fabrication costs, is developed and used in an example. The design of the girder is controlled by the 1369 MASHO code.

Due to the complex loadings required on a highway bridge, the method of influence lines is used in the analysis. The analysis portion of the program produces the design conditions for the problem, which are used to design and optimize the required girder.

Since the number of possible desiens is falrly limited, the program uses the exhaustive search technique. The techniques of interval halving and dynamic programming are also used within the design program. Interval halving is used to 
Digitized by the Internet Archive in 2011 with funding from

LYRASIS members and Sloan Foundation; Indiana Department of Transportation 
determine the thicknesses of the cover plates for the subelements, and dynamic programming is used to determine the optimum location of the cover plate splices. The computer program developed solves the simple-span problem as well as a continuous girder of up to four spans. The girder can be either composite or noncomposite and is designed for static and fatigue loads. All of the design details are developed and then listed in the putput. No attempt is made to design the girder for deflection, but the total deflections for the final design are tabulated. The engineer has the option to optimize the design based on either the total weight or the total cost. 


\section{INTRODUCTION}

Optimization is the process of obtaining "the best" solution to a problem based on a given criterion. Structural optimization, therefore, is the process of obtaining the "optimum" solution to a structural problem. This optimization is obtained by using analysis and design theory and an optimumseeking method suited to the problem.

The formulation of the optimization problem depends on the type of structure being designed. For any problem, the design variables, the design constraints and the criterion of the optimization (the objective function) must be defined. Values of the design parameters are desired so that the value of the objective function is a minimum or maximum, as required, and the constraints are not violated.

The design parameters required depend on the type of optimization problem and on the theoretical equations used. The specification used to control the design specifies the necessary constraints for the problem. In most problems, both equality and inequality constraints are used.

'The objective function can be any desirable measure of the effectiveness of the design. Some of the measures which have been used are weight, cost, cost-benefit ratios, and reliability. For the highway bridge girder, minimum weight has been used for many years, because of the relationship which exists between weight and cost. For the problem studied in this paper, however, the cost function used is more realistic because it includes the fabrication costs (3).

The methods used to solve optimization problems can be divided into direct and indirect methods. The indfrect methods are mathematical methods which can use the gradient of the algebraic form of the objective function to solve a given problem. Direct methods are ones which make trial solutions in some organized manner. The solutions are compared and a final optimum is chosen. Each of the 
types has its own advantages and disadvantages when used in a particular structural optimization problem.

The optimization of girders has been extensively approached in the past by using minimum weight as the measure of effectiveness $(8,9,11,12)$. The procedure has been to minimize the cross-sectional area of the girder. This in turn minimizes the weight of the structure $(4,10)$.

The total cost optimization has been developed for both building and bridge girders. The method of backtrack programming has been used to optimize the design of welded plate girders for buildings (1). The total cost optimization work on highway bridge girders $(5,14,13)$ has led to the development of a computer program referred to as Girder Automated Design - I or GAD - I $(6,7)$. The program completely designs the constant depth plate girder and specifies all of the design details, including the flange thicknesses, the flange splice locations and the locations of the transverse and longitudinal stiffeners if they are required.

Since the GAD - I program has been developed, it has been possible to design the optimum welded plate girder for a highway bridge. This girder, however, is not necessarily the actual optimum design for the problem. There is a possibility that either a composite or noncomposite rolled-section girder may be more economical. This is particularly true if the spans of the girder are relatively short.

In the present computer program development, the AASHO code (2) is used to control the design of a highway bridge eirder. The cross section of the girder is limited to the 33- and 36-in. wide-flange rolled sections. The design can be efther composite or noncomposite and can have cover plates if they are required. The girder is designed for all required static and fatigue highway loads. The fatigue conditions are based on 500,000 cycles of stress. If the design is composite, 7/8-in. diameter shear connector studs are provided at the proper spacing. 
The method of exhaustive search is used in the program because of the limited number of rolled sections of proper size. Each of the eighteen possibilities is designed, using the method of interval halving to solve for the required cover plate thicknesses. The method of dynamic programming is used to determine the optimum location of the cover plate splices.

\section{GIRDER ANALYSIS}

The first problem that confronts the designer of a particular structure is to determine the required design-load conditions. These conditions usually vary with the size, purpose and location of the structure. The actual conditions are often designated by design specifications and can be found in design codes.

The necessary design loads for a highway bridge girder are specified by the AASHO code. The code requires that the bridge structure must be designed for the largest truck load and the corresponding equivalent lane load which the bridge must sustain. The bridge may also be designed for an interstate loading condition and for a sidewalk loading condition if pedestrian walkways are provided on the bridge. These four types of loads constitute the live-load conditions for a highway bridge.

Besides the above live loads, the bridge must be designed for the required dead-load conditions. Dead loads include the weight of the steel girder, the weight of the deck slab, and the weight of the bridge railings and light fixtures. If the design is noncomposite, then all of these loads are combined into one deadload condition. If the design is composite, the loads are separated into two groups because they are resisted by different sections. The first group acts on the steel girder only and the second acts on the low modulus composite section. The second group is referred to as the superimposed dead load or the long-term live load. 
Once the loads which act on the structure have been defined, the stresses caused by these loads must be determined. The design loads must be placed on the structure so that maximum design conditions are developed at the critical points in the structure. The determination of these design values constitutes a complete analysis of the structure being designed.

Since the loading conditions, as shown above, for the highway bridge girder are complex in nature, the method of influence lines is used to produce the design conditions. This method makes it possible to subject the structure to a large number of loading conditions and to choose the controlling maximum from these conditions.

The first step in the analysis is to determine the influence coefricients for the reactions. These coefficients can be calculated by using equilibrium and compatability equations. These equations can be set up in matrix form and the resulting reaction influence coefficients can be determined by some method common to matrix algebra. With these values, the moment and shear influence coefficients at any point are easily determined by simple statics.

With the solution to all of the influence lines complete, any line can be chosen and loaded. Using the available influence line theories, all of the design conditions for the problem can be determined. The girder can then be designed and optimized for these conditions.

\section{ROLLED SECTION DESIGN}

With the design conditions defined at each analysis point, the crosa section can be proportioned to carry the necessary design stresses. The design of a particular rolled section can be determined in the following four steps:

1. Determine the required cover plates for the given section, 2. Design the cover plate welds for the section, 
3. Determine the shear connector spacing if the given section is designed for composite action,

4. Design the bearing stiffeners if they are required for the given section.

With these four steps, any rolled section can be designed to carry the stresses determined in the analysis portion of the problem.

The determination of the cover plates for a particular rolled section requires the following five steps:

1. Determine the plate width,

2. Determine the maximum moment for each subelement,

3. Calculate the required plate thickness for each element,

4. Determine the cutoff location for each of the required cover plate tinicknesses,

5. Optimize the cover plate splice locations.

Since the required width of a cover plate is only dependent on the size of the rolled section, the width of the flange is used to determine the plate width. The range of flange widths for the 33 - and 36-in. wide-flange sections is approximately $11.5 \mathrm{in.}$ to $16.5 \mathrm{in.} \mathrm{For} \mathrm{ease} \mathrm{of} \mathrm{fabrication,} \mathrm{the} \mathrm{cover} \mathrm{plate} \mathrm{should} \mathrm{be}$ narrower than the flange. If the cover plate width is specifled in whole inches, then Table 1 shows the plate widths used in the program for all the required sections. The smaller plate sizes provide approximately $11 / 4 \mathrm{ln}$. to $21 / 4 \mathrm{ln}$. on each side of the plate. This makes it readily posstble to weld the plate to the flange of the rolled section.

Before determining the thickness of the plate required for a given element, the governing moment for the element must be determined. For an element I, shown in Flgure 1, the governing moment is found at elther point 1 or $1+1$. If the dead-load moment at the end points are of the same sign, then the total 


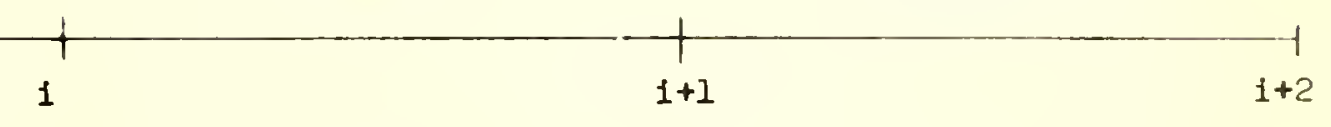

i
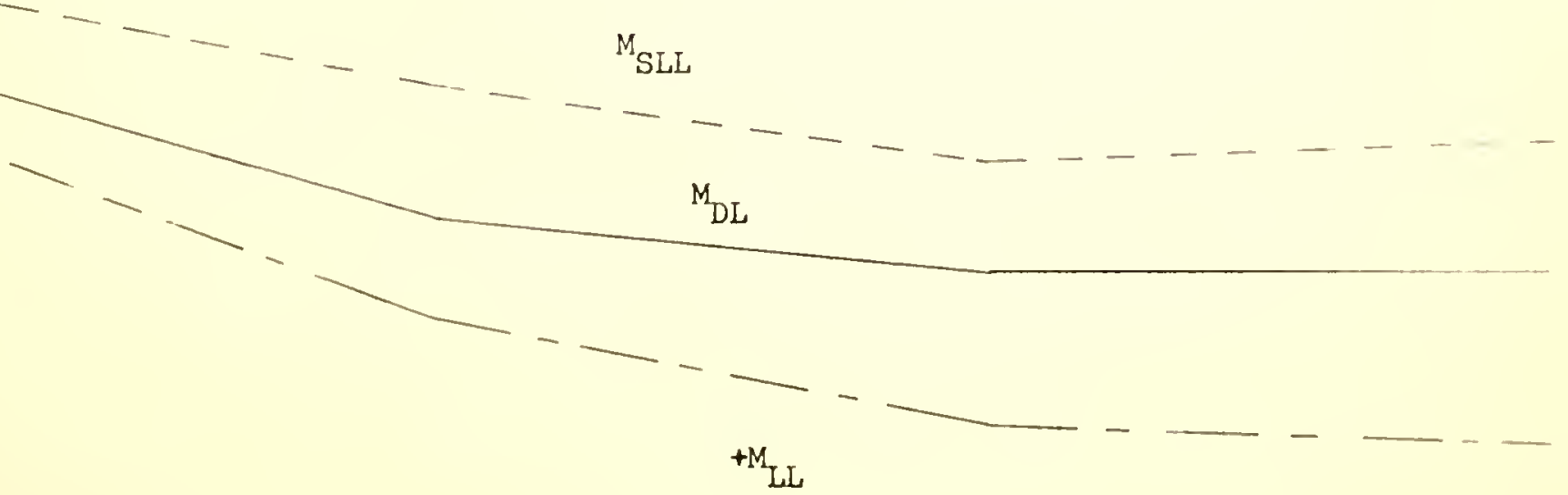
Table 1: Required Cover Plate Widths

\begin{tabular}{|c|c|c|}
\hline Section & Range of $f_{W}(i n)$. & $b($ in. $)$ \\
\hline W33x118 - W33x152 & $11.484-11.565$ & 9 \\
\hline w36x135 - w36x194 & $11.945-12.117$ & 9 \\
\hline$W 33 \times 200-W 33 \times 240$ & $15.750-15.865$ & 12 \\
\hline W36 $3230-w 36 \times 300$ & $16.475-16.655$ & 12 \\
\hline
\end{tabular}

maximum moments are determined at each end. The plate thickness is then calculated for the location which contains the larger total moment. If there is a change in the sign of the dead-load moment within the subelement, the thickness is calculated for the set of moments at the negative dead-load moment location. The cover plate cutoffs are subsequently determined in such a manner to insure that the girder is not overstressed at any point.

After the governing moments are determined, the rolled section is tried without cover plates. If all the stress conditions are satisfied, then the plate width and plate thickness for the subelement are set equal to zero and the calculations for the subelement are complete. If the stress conditions are violated, then the required cover plate thickness must be determined.

The steel cross sections used in a rolled-section girder are shown in Figure 2. A symmetrical section is used in the negative moment region (Figure $2 a$ ). The equation for the cover plate thickness can be derived by using the flexure formula. The third-order equation for the thickness is

$$
\frac{2}{3} t^{3}+d t^{2}+\left[\frac{a^{2}}{2}-\frac{\text { tot }}{b f_{a l l}}\right] t=\frac{M_{\text {tot }} d}{2 f_{a l l} b}-\frac{I_{x x}}{b}
$$

'The equation for the cover plate thickness in the positive moment repion is extremely complex when compared to liquation 1. This thickness equation is derived from the following, form of the flexure formula:

$$
\mathrm{f}_{\mathrm{all}}=\frac{\mathrm{M}_{\mathrm{DL}}^{\mathrm{y}} \mathrm{st}}{I_{s t}}+\frac{M_{L L} \mathrm{y}_{h m c}}{I_{h m c}}+\frac{M_{S L} \mathrm{y}_{I m c}}{I_{\text {lmc }}}
$$




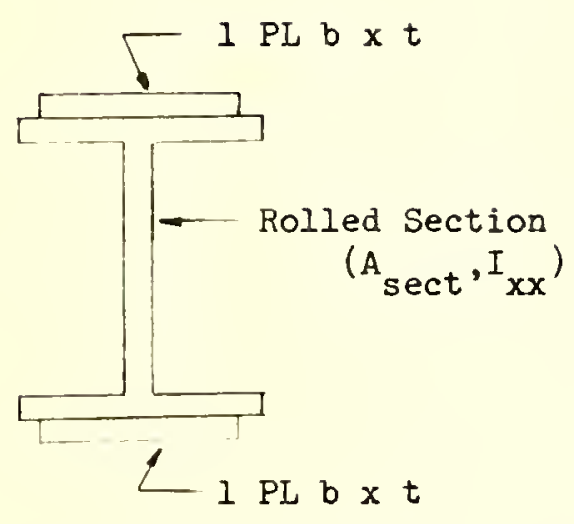

2a: Negative Moment Cross Section

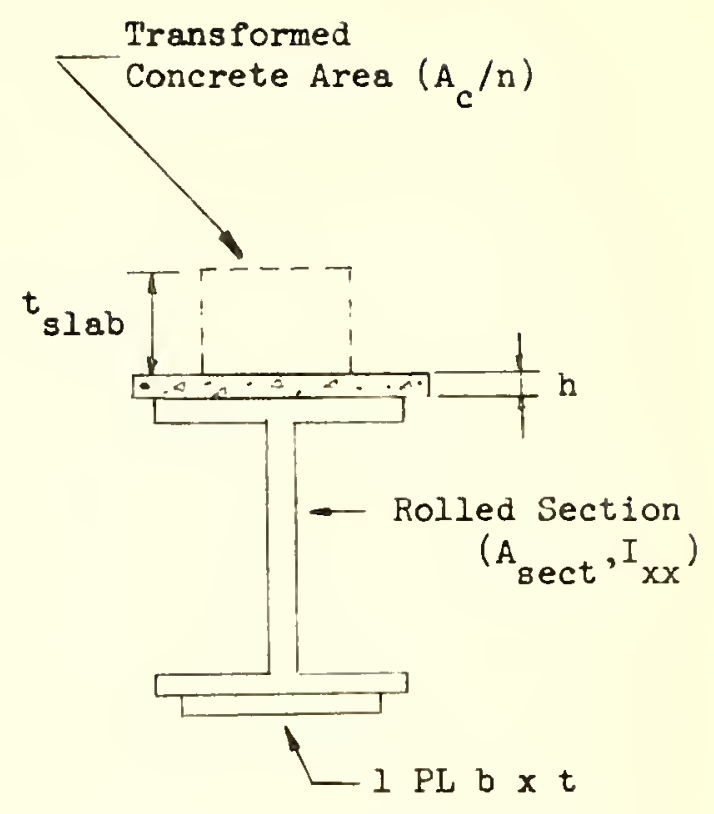

2b: Positive Moment

Cross Section

Fig. 2: Steel Cross Sections 
All of the moments of inertia and the extreme fiber distances are functions of the cover plate dimensions. The functional equation for the thickness, therefore, is

$$
t=F\left(M_{D L}, M_{L L}, M_{S L}, f_{a l l}, b, I_{x x}, n, A_{c}, t_{s}, A_{\text {sect }}, d, h\right)
$$

Since both Equations 1 and 3 are complex in nature, a direct method of solution is inappropriate. The method of interval halving is used to reduce the number of calculations necessary for each thickness determination.

The technique of interval halving uses a bounded interval which is continuously reduced in size until a certain tolerance is obtained. In order to reduce the interval by one-half with each calculation, the function must be continuously increasing or decreasing. Figure 3 shows that the relationship between the cover plate thickness and the extreme fiber stress satisfies this condition. By specifing the initial boundary conditions, the interval halving process can be started and used to calculate the thickness which gives a bending stress equal to $\mathrm{f}_{\mathrm{all}}$. Any thickness which is larger than $\mathrm{t}_{\text {req'd }}$ is not economical and any thickness less than $t_{r e q}{ }^{\prime}$ produces stresses which violate the stress constraints. The initial values of the boundaries, $t_{\max }$ and $t_{\min }$, are specified by the design constraints.

Steel plates are commercially available in thickness increments of $1 / 16$ in. The interval halvinf, process, therefore, must produce thicknesses which are multiples of $1 / 16 \mathrm{in.}$ The initial interval must be specified such that the midpoint of each subdivision is an exact multiple of .0625 in. The boundaries for the initial interval must be separated by $1 / 16$ in. times an integral power of 2 . The initial lower boundary (BL) and the inttal upper boundary (UL) used in the program are determined by Equation 4:

$$
\begin{array}{ll}
\text { If } t_{f} \leq 1.44 \mathrm{in.}, & \mathrm{BL}=5 / 16 \mathrm{in} . \text { and } \mathrm{UL}=25 / 16 \mathrm{in} . \\
\text { If } \mathrm{t}_{\mathrm{f}} \geq 1.44 \mathrm{in} ., & \mathrm{BL}=7 / 16 \mathrm{in} . \text { and } \mathrm{UL}=27 / 16 \mathrm{in} .
\end{array}
$$


All of the thicknesses determined from these initial starting boundaries, satisfy the width-to-thickness ratios for cover plates which are specified by AASHO.

With the initial interval specified, the plate thickness is set equal to the interval midpoint. If the $M_{D L}$ is positive, then just a bottom plate is required. If $M_{D L}$ is negative, then plates are used on the top and bottom of the rolled section. The properties of the defined steel section are determined and the bending stresses are calculated.

The allowable static and fatigue stresses are then determined and compared to the actual bending stresses. If the allowable stresses are not violated, then the upper bound of the interval is set equal to the interval midpoint. This completely eliminates the upper half of the interval as being not as economical as the midpoint. If the allowable stresses are violated, then the midpoint becomes the lower bound. This eliminates the lower half of the interval because the thicknesses do not satisfy the stress conditions. The process is continued, using the new interval, until a final interval of less than $1 / 16$ in. is obtained. The $t_{r e q} d$ is then equal to the boundary value which satisfies all of the stress conditions.

The method of interval halving greatly reduces the required number of calculations required to solve the thickness equations. The thickness of any subelement can be determined by considering only rive different plate thicknesses. For example, if the required plate thickness for a w36\%160 section is 1 in., the plate thicknesses which must be tried are $15 / 16,13 / 16,11 / 16,15 / 16$, and 1 in. The interval sizes and boundaries used in this determination are shown in Table 2. If all the thicknesses between $5 / 16$ and 1 in. were calculated, twelve series of calculations would be necessary. The interval halving technique reduces this number to five, thus reducing the necessary computation costs. This saving would be even greater if the cover plate thickness were greater than 
1 in.

Table 2: Interval Data for the Sample Example

\begin{tabular}{|cccc|}
\hline Series & UL & BI & Midpoint \\
\hline 1 & $25 / 16$ & $5 / 16$ & $15 / 16$ \\
2 & $15 / 16$ & $5 / 16$ & $13 / 16$ \\
3 & $15 / 16$ & $13 / 16$ & $11 / 16$ \\
4 & $11 / 16$ & $13 / 16$ & $15 / 16$ \\
5 & $11 / 16$ & $15 / 16$ & 1 \\
\hline
\end{tabular}

Using interval halving, the required plate thickness for each subelement can be determined. Once this is complete, tne cutoff location for each plate end must be caiculated. These cutoffs are based on static and fatigue stress requirements. The fatigue formula specified in the 1969 AASHO code is

$$
\begin{gathered}
F_{r}=\frac{k_{1} f_{r o}}{1-k_{2} R} \\
\text { where } k_{1}=1.0+a\left(\frac{F_{u}}{58000}-1\right)
\end{gathered}
$$

The fatigue constants, $k_{2}$, $f_{r o}$, and $\alpha$, are based on the location, the type of stress under consideration and the number of stress cycles. All of the fatigue constants used in the computer program are based on 500,000 cycles of stress. If the location of the stress is the end of a cover plate, the allowable fatifue stress is

$$
F_{r}=\frac{12000}{1-R}
$$

The fatigue equations for two cover plates butt welded together are

$$
\begin{aligned}
& F_{r}=\frac{17200 k_{1}}{1-.62 R} \quad \text { for tension } \\
& F_{r}=\frac{.55 F y}{I-\left(\frac{.55 F y}{10600 k y}-1\right) R} \text { for compression }
\end{aligned}
$$


For a given point on the girder, the stresses are calculated and compared to the allowable stresses found using Equation 6 or 7 . For simplicity, the static stress is also checked at the actual cutoff rather than at the theoretical cutoff location as specified in the AASHO code. The reason for this is to save the calculation cost required for the added moment interpolation. If the actual stresses are less than the allowables, the plate can be cut off into a hipher moment region, thus saving in plate cost. The cover plate must be extended into a lower moment region if the stress conditions are violated. This results in an added cost which is necessary to insure that the deslgn constraints are not violated.

The cutoff distance for a particular plate is determined by using an increasing step size technique. The initial step size is set equal to 1 in. if the plate is to be cut or extended to the right. A negative value is used if the cutoff or extension is to the left. This step is referred to as DIST in the program.

For a particular step size, the moments are determined by straight line interpolation and the maximum stresses are determined. The maximum is compared to the allowable and the step size is doubled. The process is continued until a location which has the stress just equal to the allowable is determined. If, at any time during the cutoff operation, the actual location $1 \mathrm{~s}$ passed, the last acceptable location is retained and the step size is initialized at I in. The process is then continued from the last acceptable location. This enables the cutoff point to be located to the nearest inch.

Throughout the cutoff operation, provision is made for many unique occurrences. Some of these provisions are:

1. Extension of a cover plate through a section of zero thickness,

2. A maximum cutoff distance is set and not exceeded, 
3. The minimum length cover plate is suppliea over the interior supports,

4. Complete elimination of a thinner plate by a thicker plate.

All of the above situations must be and are considered in the design.

With the completion of the cutoff for each cover plate thickness, the total cover plate syster for a particular rolled section is defined. The size of each required cover plate between certain coordinates is now specified. The total cost of the system must now be minimized and the optimum location of the splice points must be determined. This optimization is achieved by using dynamic proEraming.

Dynamic programming is a method used to optimize sequential problems. It can be applied to situations in which many decisions must be made, as long as the decisions made at later stages do not affect the performance of the earlier stages. The method decomposes the problem into a set number of individual problems. In determining the optimum condition for a section, the only quantities involved are the variables in the next adjacent section and the value of the objective function for the system up to and including the preceding section.

The use of dynamic programing in optimizing steel girder flanges was developed by Goble and DeSantis $(5,6,7)$ and Razanni (13, 14). The method was used to determine the optimum location of the flange splices in the GAD-I program. The use of the method, to determine the splice locations for cover plates, is an extension of the method used for the welded plate girders.

In using the technique to determine the splice locations for each cover plate on a rolled section, the variable which is desired for each section is the plate thickness and the objective function is the total cost of the cover plate system. The sequence of sections is defined by the required thicknesses which have been 
previously determined. Each section has a required thickness, a required plate width, a starting coordinate and a final coordinate. The governing cost equation for a particular section is

$$
c_{1}=C_{m}+C_{s w}+C_{e w}
$$

where $C_{m}$ is the cost of the material, $C_{s w}$ is the seal weld cost and $C_{e w}$ is the end weld cost.

The cost of any weld can be determined from Equation 9:

$$
C_{\text {weld }}=C_{1}+C_{2}(V)+C_{3}(L)
$$

In Equation 9, $C_{1}$ is the fixed cost of the given weld, $C_{2}(V)$ is a variable cost based on the volume of the weld material and $C_{3}(L)$ is a variable cost based on the length of the weld. The equation for the cost of a fillet weld is

$$
c_{\text {fillet }}=c_{1}+1 / 2 t_{w}^{2} L_{w} c_{2}+L_{w} c_{3}
$$

and the equation for the cost of a butt weld is

$$
c_{\text {butt }}=c_{1}+\left(.125 t_{w}+.289 t_{w}^{2}\right) L_{w} c_{2}+L_{w} c_{3}
$$

The fillet weld cost is based on a weld cross section of an equilateral triangle with sides of $t_{w}$. The butt weld cost is based on the cross section of a standard double-vee butt weld having a thickness of $t_{w}$.

The initial step in the dyanmic programming sequence is to set up a working array. This array is the PTH array and contains all of the information regarding the required cover plates. The information for a cover plate section I is

$$
\begin{aligned}
& \text { 1. } \operatorname{PTH}(I, I)=t_{\text {req }}{ }^{\prime d}, \\
& \text { 2. } \operatorname{PTH}(I, 2)=\text { the width of the required plate, } \\
& \text { 3. PTH }(I, 3)=\text { the starting coordinate of the section, } \\
& \text { 4. } \operatorname{PTH}(I, 4)=\text { the final coordinate of the section. }
\end{aligned}
$$




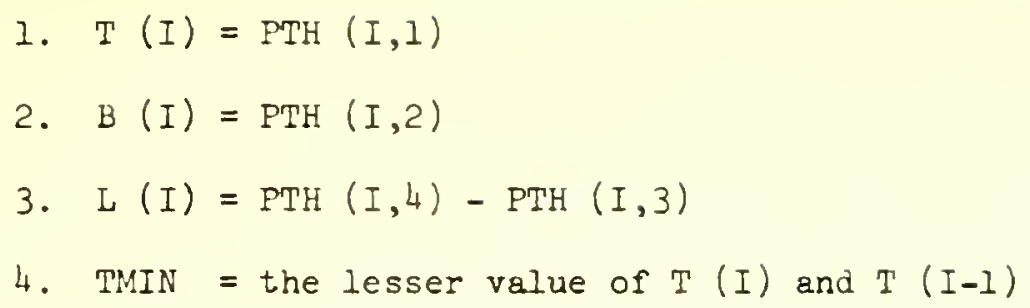

There are actually four different conditions which must be treated in the optinization of the cover plates. These conditions lead to four equations which can be used to determine the total cost of the system up to and including section I. The four conditions and equations are:

$$
\begin{aligned}
& \text { 1. Condition } I-T(I)=0.0 \text { and } T(I+I)>0.0 \\
& C_{I}=C_{1 e f t}+3 c_{1}+B(I+I)\left(c_{3}+I / 2 c_{2} t_{w}^{2}\right)
\end{aligned}
$$

where $C_{\text {left }}$ is the cost of the cover plate system to the left of section I for the value of $\mathrm{T}(I)$ used.

$$
\begin{aligned}
& \text { 2. Condition } I I-T(I)>0.0 \text { and } T(I+I)=0.0 \\
& C_{I}=C_{\text {left }}+L(I) T(I) B(I) c_{m} \frac{490}{1728}+c_{I}+B(I)\left(c_{3}+1 / 2 c_{2} t_{w}^{2}\right) \\
& +2 L(I)\left(c_{3}+.00673 c_{2}\right) \\
& \text { 3. Condition III - } T(I) \neq T(I+I) \\
& C_{I}=C_{\text {left }}+L(I) T(I) B(I) c_{m} \frac{490}{1728}+c_{I}+2 L(I)\left(c_{3}+.00673 c_{2}\right) \\
& +B(I) c_{3}+\left(.125 \mathrm{TMIN}+.289 \mathrm{TMIN}^{2}\right) \mathrm{B}(I) \mathrm{c}_{2} \\
& \text { 4. Condition IV }-T(I)=T(I-I) \\
& C_{I}=C_{\text {Ieft }}+L(I) T(I) B(I) c_{m} \frac{490}{1728}+2 L(I)\left(c_{3}+.00673 c_{2}\right)
\end{aligned}
$$

The following assumptions are used in developing Equations 12 to 15:

1. The end welds are of the minimum thickness required for the plate being used,

2. The end welds are across the end of the plate only, 
3. The minimum size seal weld (5/16 in.) is used in all cases. The dynamic programming process, for a section I, consists of using either Equation 12, 13, 14 and 15 to calculate the total cost of the plate system. Using a set thickness in section $I+I$, the plate thickness in section $I$ is varied and all the costs are calculated. The thickness of a section is varied from treq'd to the maximum thickness required on the rolled section. All of the different thicknesses required on rolled section are calculated. For a given thickness in section $I+1, T(I+1)$, the optimum thickness in section $I$ can be chosen directly. This optimum thickness can then be placed in a storage array for future use.

The thickness storage array, TP, is a two-dimensional array having one row for each cover plate section and one column for each plate thickness. The TP(I,J) element contains the optimum thickness for section I when the thickness in section $I+I$ equals STTH $(J)$. The STTH array contains all of the required plate thicknesses arranged in ascending order.

The cost of the final section is calculated for all of the available thicknesses and the optimur thickness is determined directly. With this thickness, all of the other thicknesses are determined from the TP array by working from right to left along the girder. With these thicknesses determined, the information in the PTu array is converted into the actual cover plate information and is stored in the proper location in the COVPL array.

To further explain the method of dynamic programming and its use in optimizing the cover plates of a rolled section, a sample problem is presented. Shown in Figure $4 \mathrm{a}$ is a required cover plate arrangement. Using $c_{m}=\$ .15 /$ pound, $c_{1} \$ 30.00 /$ pound and no volume or length cost for a weld, the dynamic programming process is approached as follows:

1. Set up the STTH array. STIH $=(0.0,0.5,1.0)$ 


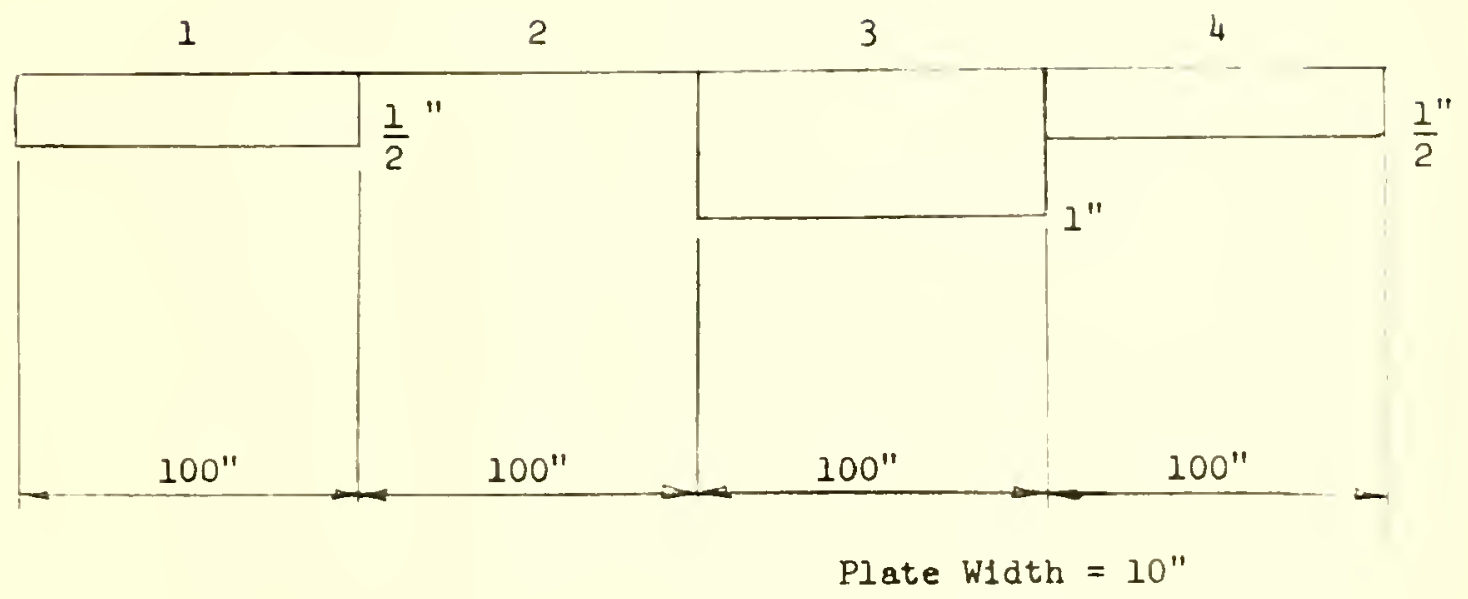

4a: Required Cover Plate Arrangements

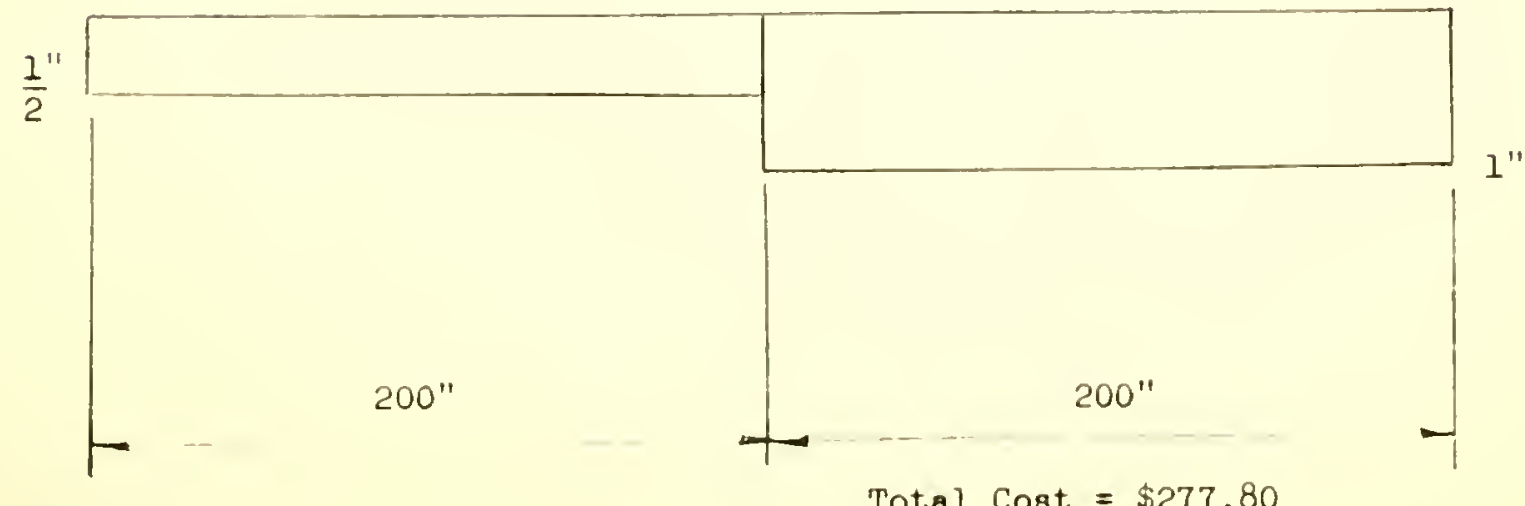

$4 \mathrm{~b}$ Optimum Cover Plate Arrangement

F1g. 4: Cover Plate Optimization Example 
2. Calculate the cost of section I for all the possible thickness combinations.

\begin{tabular}{|rrrrrr|}
\hline$T(I)$ & $T(2)$ & Equation & $C_{\text {left }}$ & $C_{\text {sect }}$ & $C_{1}$ \\
\hline .5 & 0.0 & $13^{*}$ & 0.0 & $\$ 141.30$ & $\$ 141.30$ \\
1.0 & 0.0 & $13^{*}$ & 0.0 & $\$ 162.60$ & $\$ 162.60$ \\
.5 & .5 & $15^{*}$ & 0.0 & $\$ 111.30$ & $\$ 111.30$ \\
1.0 & .5 & $14^{*}$ & 0.0 & $\$ 162.60$ & $\$ 162.60$ \\
.5 & 1.0 & $14^{*}$ & 0.0 & $\$ 141.30$ & $\$ 141.30$ \\
1.0 & 1.0 & $15^{*}$ & 0.0 & $\$ 132.60$ & $\$ 132.60$ \\
\hline
\end{tabular}

* The equation has been altered slightly to include the initial fixed cost of the seal welds and the initial end weld cost.

3. Place the appropriate values in the TP array.

\begin{tabular}{|c|c|c|c|}
\hline & 0.0 & 0.5 & 1.0 \\
\hline$P=1$ & .5 & .5 & 1.0 \\
\hline
\end{tabular}

4. Calculate the costs for section 2 for all of the thickness combinations.

\begin{tabular}{|rccccc|}
\hline$\Gamma(2)$ & $\Gamma(3)$ & Equation & $C_{\text {Ieft }}$ & $C_{\text {sect }}$ & $C_{1}$ \\
\hline 0.0 & 1.0 & 12 & $\$ 141.30$ & $\$ 90.00$ & $\$ 231.30$ \\
.5 & 1.0 & 14 & $\$ 11.30$ & $\$ 51.30$ & $\$ 162.60$ \\
1.0 & 1.0 & 13 & $\$ 132.60$ & $\$ 42.60$ & $\$ 175.20$ \\
\hline
\end{tabular}

5. Place the appropriate values in the TP array.

\begin{tabular}{|c|c|c|}
\hline 0.0 & 0.5 & 1.0 \\
\hline .5 & .5 & 1. \\
\hline
\end{tabular}

$\mathrm{TP}=$ .5 
6. Calculate the costs for section 3 for all of the thickness combinations.

\begin{tabular}{|cccccc|}
\hline $\mathrm{T}(3)$ & $\mathrm{T}(4)$ & Equation & $\mathrm{C}_{\text {Ieft }}$ & $\mathrm{C}_{\text {sect }}$ & $\mathrm{C}_{1}$ \\
\hline 1.0 & .5 & 14 & $\$ 162.60$ & $\$ 72.60$ & $\$ 235.20$ \\
1.0 & 1.0 & 15 & $\$ 162.60$ & $\$ 42.60$ & $\$ 205.20$ \\
\hline
\end{tabular}

7. Place the appropriate values in the TP array.

\begin{tabular}{|c|c|c|c|c|}
\hline & & 0.0 & 0.5 & 1.0 \\
\hline & 1 & .5 & .5 & 1.0 \\
\hline $\mathrm{TP}=$ & 2 & & & .5 \\
\hline & 3 & & 1.0 & 1.0 \\
\hline
\end{tabular}

8. Determine the optimum thickness in section 4.

\begin{tabular}{|ccccc|}
\hline T(l) & Equation & $C_{\text {Ieft }}$ & $C_{\text {sect }}$ & $C_{\text {total }}$ \\
\hline .5 & 13 & $\$ 235.20$ & $\$ 51.20$ & $\$ 286.40$ \\
1.0 & 13 & $\$ 205.20$ & $\$ 72.60$ & $\$ 277.80$ \\
\hline
\end{tabular}

The optimum $\mathrm{T}(4)$ is $1.0 \mathrm{in.}$

9. Using the TP array (Step 7), choose the thickness

for each section.

$$
\begin{array}{ll}
\mathrm{T}(4) & 1.0 \mathrm{in} . \\
\mathrm{T}(3) & 1.0 \mathrm{in} . \\
\mathrm{T}(2) & 0.5 \mathrm{in} . \\
\mathrm{T}(1) & 0.5 \mathrm{in} .
\end{array}
$$

10. The optimum cover plate arrangement is shown in Figure $4 \mathrm{~b}$. With the completion of the dynamic programing process, the cover plates are defined for the rolled section under consideration. The design details must be calculated. These details include the design of the cover plate welds, the design of the bearing stiffencrs and the calculation of the shear connector spacine if the design is composite. In the optimization problem, each of these details 
must be completed for each design because they add a substantial cost to the girder.

The welds which must be determined for each cover plate include the end welds and the seal welds. Each of these welds is designed as a fillet weld and is expressed in values which are multiplies of a sixteenth of an inch. The end welds are designed to carry the flexural stress developed at a distance of 1.5 times the plate width from the end of the plate. The seal welds are designed to carry the maximum shear stress developed along the length of the plate. A minimum size fillet weld is specified by the code depending on the thicknesses of plates being joined.

The bearing stiffeners are required to transfer the large web shear at tne reactions to prevent web crippling. In most of the wide-flange rolled sections bearing stiffeners are not required. The AASHO code requires stiffeners in those girders which have shear stresses in excess of 75 percent of the allowable shear stress. If bearing stiffeners are required, they are designed as columns having a section composed of the stiffener plates and a portion of the web which is 18 times the web thickness in length.

The shear connectors for a composite girder are designed to transfer the horizontal shear from the slab to the steel girder. These connectors are I, aced transversely across the flange at either regular or variable spacings. The connectors are designed for futigue and checked for ultimate strength.

With the completion of the design detall calculations, the design of a rolled section is complete. The total cost of the girder can then be calculated. This cost is used in the comparison of all the desiens and the optimum can be chosen.

\section{COIPUTER PROGRAM}

The computer profram for the desien of rolled-section p, frders consista of two parts. The analysis portion is used to determine the design conditions for 
the problem and the design portion is used to determine the optimum combination of rolled section and cover plates. The entire program is composed of a MAIN program and thirty-four subroutines. The purpose of the MAIN program is to call on the subroutines in the correct sequence to produce the optimum desien for the particular girder.

The first step in solving any problem is to specify the data. There are actually two sets of data required for a problem. The rolled section properties are read directly from cards by the MAIN program. The problem data are then read from cards by the READIN subroutine. A detailed description of the data input is presented in the program description (3).

After the complete problem is defined, the initial analysis must be completew. The ANAL subroutine is used to determine an initial set of design reactions, design moments, and design shears. These conditions are then used in the first design cycie.

The design cycle is started by determining the lighest uniform section which will carry the design loads. This is accomplished by designing each section, starting with the heaviest, and procedine in descending weight order, without cover plates at the critical moment location until the lighest acceptable section is determined. By ussumine tnat the cost of the shear connectors and stirfeners for a uniform section is independent of the section used, all of the sections heavier then the one which has been determined can be eliminated from the search. This means tinat a number of rolled sections need not be desifned completely and a resulting savings in computation costs is realized.

The rolled section which is beine used as a unform section is completely designed. The objective function is then used to determine the welaht and/or cost of the design depending on the basis of the optimization. This unfform design then becomes the initial design for the problem. 
Each of the remaining lighter sections is designed using the steps described above. After each design is complete, the weight and/or cost is determined. The required measure of effectiveness is compared to the value for the present optimum design. If the design is "better", it replaces the present optimum in the storage arrays. If the design is not as economical, the present optimum is retained. After all of the sections are designed, the cycle is complete.

Using the optimum design from the previous cycle, the girder is reanalyzed and a new set of design conditions is calculated. There are three options which can now be executed by the profram. The optimum girder can be redesigned for the new conditions and this final design can be accepted as the optimum. It is also possible to specify the number of design cycles desired. If this option is used, the design cycle is repeated the required number of times and the rinal solution obtained is the optimum design.

The third, and most useful, option is a converging-moment option. The value of the critical moment is compared to the value obtained from the previous analysis. If the change in the moment is less than a percentage specified in the input, the program is terminated and the present optimum is used as the fingl solution. If the percent change is ereater than that specified, a new design cycle is started. This procedure is continued until the moments converge or until a specified maximum number op cycles is reachea.

Once the rinal design is obtalned, the required deflections are calculated based on the final distribution of the moments of inertia. All of the information pertaining to the optimum design is made available in the output. This includes the section properties, the required cover plates, the required stiffeners, the shear connector spacing and the deflections. The cost or weitht of the rinal design is also presented. 


\section{SAMPLE PROBLEM}

In order to show the usefulness of the computer program, a saple girder has been designed. The problem is originally presented in the United States Steel Highway Structures Design Handbook (15). The costs of the manual design and the computer program design are compared below.

The problem is a two-span girder having equal span lengths of $70 \mathrm{ft}$. The design is based on a composite section having the properties listed in Table 3. The design loading is the AASHO HS2O loading.

Table 3: Composite Section Properties

\begin{tabular}{|cc|}
\hline Property & Value \\
\hline Slab Width & $84.00 \mathrm{in.}$ \\
Slab Thickness & $7.00 \mathrm{in}$. \\
$\mathrm{f}^{\prime \prime}$ & $3000.00 \mathrm{psi}$ \\
Modular Ratio & 8.00 \\
Area of Steel & $4.34 \mathrm{sq} \mathrm{in.}$ \\
Haunch & $1.875 \mathrm{in}$. \\
\hline
\end{tabular}

The optimization of the Girder is based on total cost and the unit costs used in the optimization procedure are listed in Table 4.

\section{Table 4: Unit Costs}

\begin{tabular}{|lcc|}
\hline Item & Unit & Cost in dollars \\
\hline Rolled Section & Ib & 0.15 \\
Cover Plates & lb & 0.12 \\
Stiffeners & Ib & 0.12 \\
Connectors & Ib & 0.00 \\
Connector Instgllation & ea & 0.75 \\
Fixed Weld Cost & ea & 20.00 \\
Weld Material Cost & cu in. & 2.00 \\
Weld Length Cost & in. & 0.00 \\
\hline
\end{tabular}


The final design produced by the computer program is shown in Figure 5. The itemized costs and weights of both the computer solution and the manual solution are given in Table 5 .

Table 5: Itemized Costs and Weights for the Two-Span Sample Problem

\begin{tabular}{|c|c|c|c|c|}
\hline & \multicolumn{2}{|c|}{ U.S. Steel Manual } & \multicolumn{2}{|c|}{ Computer Program } \\
\hline Item & Weight & Cost & Weight & Cost \\
\hline Rolled Section & 18900.0 & $\$ 2835.00$ & 22400.0 & $\$ 3360.00$ \\
\hline Cover Plates & 2361.6 & $\$ 283.40$ & 360.1 & $\$ 31.22$ \\
\hline Stiffeners & $-\cdots-\cdots$ & ----- & ----- & $--\cdots--$ \\
\hline Connectors & 202.2 & $\$ 193.50$ & 179.8 & $\$ 174.00$ \\
\hline Vields & $-\cdots--$ & $\$ 628.29$ & -- & $\$ 207.26$ \\
\hline Totals & 21463.8 & $\$ 3940.19$ & 22839.9 & $\$ 3772.48$ \\
\hline
\end{tabular}

Table 5 shows that the optimization program produced a girder which is approximately 6.4 percent heavier than the girder found in the manual. The optimum design, however, costs 4.3 percent less than the manual design. Most of the cost reduction can be found in the cover plate cost. The total cost of the plates, includine both material and fabrication costs, for the optimum firder is $\$ 238.48$. The same costs for the manual design give a total of $\$ 911.69$ or approximately four times as much as the propram solution. This cost difference offsets the increased cost of the rolled section used in the optimum design.

The computer program used to solve this problem is approximately 4000 cards in length and was developed and executed on the CDC 6500 computer. The compliation time for the program is about 48 seconds and the exccution time for the above sunnle problems was about 40 seconds. 


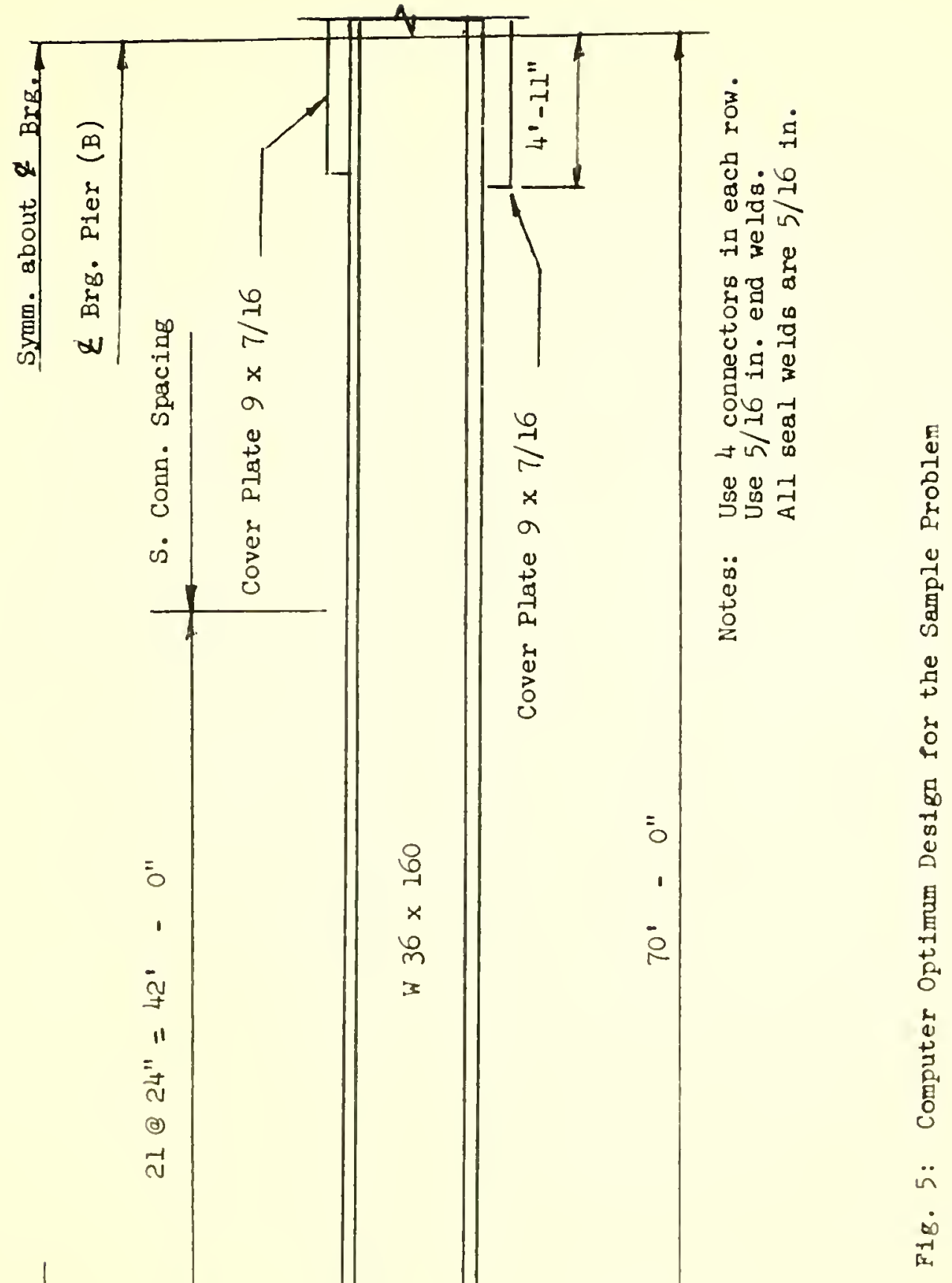




\section{CONCLUSIONS}

This computer program is another step in the automation of steel beam bridge design. The previous sample problem shows that cost savings are possible using the total cost concept in design. The digital computer makes possible the use of optimum-seeking methods in practical problems such as highway design. However, a large number of problems remain to be solved before the optimization of an entire bridge design project will be possible.

\section{ACKNOWLEDGMENTS}

The authors wish to acknowledge the financial support of the Joint Highway Research Project. The guidance and help of Professor Harold L. Michael, the Associate Director of the Project, is appreciated. The aid and support of the Indiana State Highway Comission is also appreciated.

\section{WOMENCLATURE}

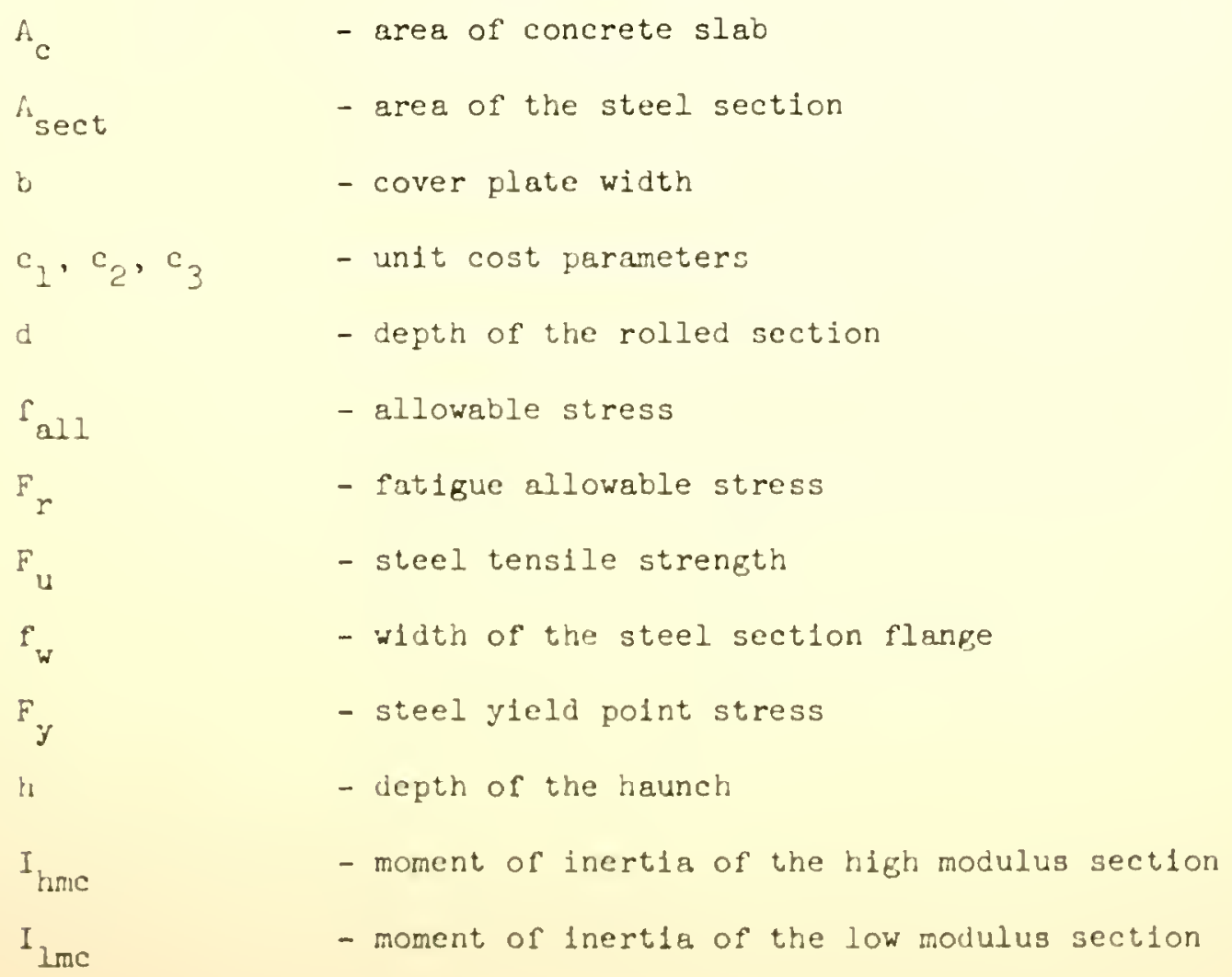


$I_{\text {st }}$

$I_{x x}$

$L_{\text {W }}$

$\because \mathrm{DL}$

${ }^{M} \mathrm{LL}$

$\because \mathrm{SL}$

$\mathrm{n}$

R

t

$t_{f}$

$t_{s}$

$t_{W}$

$y_{\text {hme }}$

$\mathrm{y}_{\mathrm{Imc}}$

$y_{s t}$
- moment of inertia of the steel section

- moment of inertia of the rolled section

- length of a weld

- dead load moment

- live load moment

- superimposed live load moment

- modular ratio

- ratio of the minimum stress to the maximum stress

- cover plate thickness

- thickness of the flange

- thickness of concrete slab

- weld size or thickness

- extreme fiber distance for the high modulus section

- extreme fiber distance for the low modulus section

- extreme fiber distance for the steel section 


\section{REFERENCES}

1. Annamalai, N.: Cost Optimization of Welded Plate Girders, Ph.D. Thesis, Purdue University, 1970.

2. American Association of State Highway Officials, Standard Specifications for Highway Bridges, Tenth Edition, 1969.

3. Busek, R. H.: Practical Optimization of Steel Highway Bridge Beams, M.S.C.E. Thesis, Purdue University, 1971.

4. Edward, C. H. and L. H. Gary: "Minimum Weight Proportions for Steel Girders", ASCE Journal of the Structural Division, Vol. 95, No. 10, Oct. 1969.

5. Goble, G. and P. V. DeSantis: "Optimum Design of Mixed Steel Composite Girders", ASCE Journal of the Structural Division, Vol. 92, No. 12, Dec. 1966.

6. Goble, G. and P. V. DeSantis: Girder Automated Design - I, Vol. 1 - User's Manual, Oct. 1968.

7. Goble, G. and P. V. DeSantis: Girder Automated Design - I, Vol. 2 - Maintenance Manual, Oct. 1968.

8. Hahn, E. W.: Minimum Weight Elastic and Plastic Design of Beams and Simple Structures, Ph.D. Thesis, June 1969, Purdue University.

9. Haug, E.: Minimum Weight Design of Beams with Inequality Constraints of Stress and Deflection, Ph.D. Thesis, 1966 , Kansas State University.

10. Holt, E. C. and G. I. He1thecker: "Minimum Weight Properties for Steel Girders", ASCE Journal of the Structural Division, Vol. 95, No. 10, Oct. 1969. 
11. Krishman, S. and K. V. Shetty: "On the Optimum Design of an I-Section Beam", Journal of Aerospace Science, No. 26, 1959.

12. Krishman, S. and K. V. Shetty: "A Method of Minimum Weight Design for Thin-Walled Beams", Structural Engineer, No. 5, 1961.

13. Razani, R.: The Iterative Smoothing Method and Its Application to Minimum Cost Design of Highway Bridge Girders, Ph.D. Thesis, 1965, Case Institute of Technology.

14. Razani, R. and G. Goble: "Optimum Design of Constant Depth Plate Girders", ASCE Journal of the Structural Division, Vol. 92, Apr. 1966.

15. United States Steel Company: Highway Structures Design Handbook, Volumes 1 and $2,1965$. 

